\title{
Desempenho e desenvolvimento corporal de bovinos leiteiros mestiços submetidos a níveis de suplementação em pastagem de Brachiaria brizantha
}

\author{
Performance and body development crossbred dairy cattle submitted to levels of supplementation in \\ Brachiaria brizantha
}

\begin{abstract}
Pedro Leonardo de Paula Rezende ${ }^{\mathrm{I}}$ João Restle ${ }^{\mathrm{II}}$ Juliano José de Resende Fernades ${ }^{\mathrm{I}}$ João Teodoro Pádua ${ }^{\mathrm{I}}$ Marcondes Dias de Freitas Neto ${ }^{\mathrm{I}}$ Filipe Marinho da Rocha ${ }^{\mathrm{I}}$
\end{abstract}

\section{RESUMO}

\begin{abstract}
Estudou-se o efeito dos níveis de suplementação energética, em pastagem de Brachiaria brizantha, sobre o desempenho e o desenvolvimento de medidas corporais de bovinos mestiços de origem leiteira na fase de desenvolvimento inicial. $O$ experimento foi conduzido em 126 dias, divididos em seis períodos de 21 dias, correspondendo a segunda metade do período de chuvas e início do período seco. Foram utilizados 24 bovinos mestiços não castrados Holandês/Zebu, com 6 meses de idade e $118^{ \pm} 16 \mathrm{~kg}$ de peso vivo no início do experimento. Os tratamentos foram determinados pelo fornecimento de suplemento energético em quantidade equivalente a 0,5 ou $1,0 \%$ do peso vivo. Constatou-se interação significativa entre os tratamentos e períodos experimentais sobre o ganho em peso médio diário. Animais do grupo de alto nível de suplementação (NA) mantiveram o GMD mais elevado e mais constante com a evolução dos períodos $(0,95 ; 1,09 ; 1,07$; 1,$00 ; 0,93$ e 0,23kg dia $\left.{ }^{-1}\right)$, resultando em maior peso final $(231,26$ vs 197,55kg), enquanto que os animais do tratamento de médio nível de suplementação (NM) apresentaram maiores oscilações de GMD entre os períodos $(0,83 ; 0,59 ; 0,75 ; 0,78$; 0,44 e $\left.0,35 \mathrm{~kg} \mathrm{dia}^{-1}\right)$. O grupo NA apresentou maiores patamares para as medidas finais $(\mathrm{cm})$ de perímetro torácico $(146,02 \mathrm{vs}$ 136,44); comprimento $(108,35$ vs 103,22); altura da garupa (120,38 vs 112,46); altura da cernelha $(113,91$ vs 110,62) e não diferiu quanto ao perímetro escrotal e de canela.
\end{abstract}

Palavras-chave: ganho em peso, perímetro torácico, medidas corporais, suplementação.

\section{ABSTRACT}

It was studied the effect of energy supplementation levels in Brachiaria brizantha on performance and development of body measurements in crossbred dairy cattle at early growth stages. The experiment was conducted in 126 days, divided into six periods of 21 days, corresponding to the second half of the rainy season and early dry season. It was used 24 crossbred non-castrated Holstein / Zebu, with 6 months of age and $118+$ $16 \mathrm{~kg}$ live weight at the start of the experiment. Treatments were determined by the supply of energy supplement in an amount equivalent to 0.5 or $1.0 \%$ of body weight. It was found a significant interaction between treatments and experimental periods on the average daily weight gain. Animals with high level of supplementation (NA) had the highest and more constants $A D G$ with the elapsing periods $(0.95,1.09,1.07$, $1.00,0.93$ and $\left.0.23 \mathrm{~kg}^{\text {days }}{ }^{-1}\right)$, resulting in higher final weight (231.26 vs. $197.55 \mathrm{~kg})$, while animals fed with the medium level of supplementation ( NM) had higher ADG oscillations between periods $\left(0.83,0.59,0.75,0.78,0.44\right.$ and $\left.0.35 \mathrm{~kg} \mathrm{day}^{-1}\right)$. The NA group showed higher final measures $(\mathrm{cm})$ of girth (146.02 vs 136.44), length (108.35 vs 103.22), croup height (120.38 vs. 112.46), withers height (113.91 vs 110.62) and did not differ for scrotal circumference and cinnamon.

Key words: gain weight, thoracic Perimeter, suplementation.

\section{INTRODUÇÃO}

Nos sistemas de produção de carne bovina do Brasil, as gramíneas forrageiras constituem a principal fonte de alimentação dos bovinos. Na macro região Centro-oeste, as espécies do gênero Brachiaria, durante a estação das chuvas, apesar de não serem consideradas deficientes em proteína bruta, possibilitam ganhos em peso aquém do potencial genético dos animais (ELIZALDE et al., 1998). Segundo

'Departamento de Produção Animal, Escola de Veterinária e Zootecnia (EVZ), Universidade Federal de Goiás (UFG), Campus Samambaia, CP 131, 74001-970, Goiânia, GO, Brasil. E-mail: pedrozootec@ hotmail.com. *Autor para correspondência.

"Conselho Nacional de Desenvolvimento Científico e Tecnológico (CNPq), Ministério de Ciência e Tecnologia, Brasília, DF, Brasil. 
EUCLIDES et al. (2003), a qualidade das gramíneas tropicais do gênero Brachiaria é mediana, permitindo ganhos em peso de aproximadamente $0,46 \mathrm{e} 0,23 \mathrm{~kg} \mathrm{dia}^{-1}$ para os períodos chuvoso e seco, respectivamente. Diante disso, torna-se relevante a necessidade de se estudar a eficiência técnica e biológica de diferentes estratégias alimentares objetivando suprir a necessidade de nutrientes limitantes para manutenção de taxas de ganho em peso satisfatórias em pastagem de gramíneas tropicais do gênero Brachiaria.

Além de a terminação ser mais eficiente em animais mais jovens (RESTLE et al., 1999), estratégias de alimentação suplementar na fase de crescimento, significam maior peso de entrada no confinamento resultando em menor tempona terminação. Dessa forma, o crescimento corporal e o nível do ganho em peso do animal antes dos 12 meses, têm reflexo em características importantes da carcaça e da carne de bovinos de corte (RESTLE et al., 1999).

A maioria dos trabalhos conduzidos no Brasil abordando produção de bovinos jovens suplementados em pastagem foi desenvolvida com animais de grupos genéticos de aptidão para corte. Há necessidade de se obter mais informações científicas com bovinos machos de origem leiteira em função da alta disponibilidade desse tipo de animal, principalmente nas regiões Sudeste e Centro-Oeste.

Assim, objetivou-se com este estudo avaliar o efeito de níveis de suplementação energética em pastagem de Brachiaria brizantha durante o período de transição águas-seca, sobre o desempenho e desenvolvimento corporal de bovinos mestiços de origem leiteira na fase de crescimento inicial pós desmame.

\section{MATERIAL E MÉTODOS}

$\mathrm{O}$ experimento foi conduzido em área pertencente à Universidade Federal de Goiás (UFG), localizada no município de Goiânia, com altitude de $771 \mathrm{~m}$, latitude $16^{\circ} 36^{\prime}$ Sul e longitude $49^{\circ} 15^{\prime}$ Oeste. Animais foram mantidos em pastagem de Brachiaria brizantha durante 126 dias, divididos em seis períodos de pastejo de 21 dias, de Fevereiro a Junho de 2008, compreendendo a segunda metade do período de chuvas e início do período seco.

Foram utilizados 24 bovinos machos mestiços (Holandês/Zebu), não castrados, provenientes de rebanho leiteiro. Os animais foram adquiridos com seis meses de idade e peso médio de $118^{ \pm} 16 \mathrm{~kg}$ no início do experimento. Os animais foram desverminados e tratados contra ectoparasitas, além das vacinações conforme o calendário profilático da região.
O ganho em peso e o desenvolvimento corporal dos animais foram avaliados em função de dois níveis de suplementação energética: Alto (NA) e Médio (NM), fornecidos em quantidade equivalente a 1,0 e $0,5 \%$ do peso vivo (PV) médio do grupo experimental, respectivamente. $\mathrm{O}$ suplemento energético utilizado foi o grão de milho triturado com 9,2\% de PB; $13,38 \%$ FDN; 4,6\% FDA; 4,06\% EE e 5,45\% de cinzas, acrescido de mistura mineral composta por $12,0 \% \mathrm{Ca} ; 8,8 \% \mathrm{P} ; 12,6 \% \mathrm{Na} ; 12,0 \% \mathrm{~S} ; 0,98 \%$ microminerais, conforme exigências sugeridas pelo NRC (1996). O suplemento foi fornecido diariamente duas vezes, às $8 \mathrm{~h}$ e $17 \mathrm{~h}$, em comedouros de suplementação com $0,5 \mathrm{~m}$ linear animal ${ }^{-1}$.

A área da pastagem possuía 17 hectares (ha) e foi utilizada em sistema rotacionado, dividida em quatro módulos de 4,25ha (dois por tratamento). Cada módulo foi subdividido em quatro piquetes em que os lotes eram manejados de acordo com a altura da pastagem, entrando com $40 \pm 5 \mathrm{~cm}$, sendo mudados de piquete quando verificada altura de pastejo inferior a $25 \pm 5 \mathrm{~cm}$ conforme sugerido por EUCLIDES et al. (1992).

A disponibilidade de forragem (DF) foi determinada utilizando quadrado de ferro com $1 \mathrm{~m}^{2}$ de área, com cortes a $10 \mathrm{~cm}$ do solo, sendo realizadas cinco amostragens por piquete, no início de cada um dos seis períodos experimentais, resultando na DF inicial média de cada período expressada em $\mathrm{kg}$ MS ha(Tabela 1).

As amostras de forragem aparentemente consumida foram coletadas, manualmente, por intermédio da técnica de simulação de pastejo (GIBB \& TREACHER, 1976) periodicamente a cada 21 dias, visando a analisar bromatologicamente o material semelhante ao consumido pelos animais. Esta amostragem foi realizada imediatamente após o período de ocupação, quando os animais eram mudados de piquete. Na mesma ocasião, determinou-se a composição da pastagem em função do percentual de folhas e colmos e a disponibilidade de forragem (Tabela 1).

As amostras de forragem, manualmente coletadas, foram pré-secas em estufa à $65^{\circ} \mathrm{C}$, moídas em moinho tipo Willey com peneira de $5 \mathrm{~mm}$, embaladas e identificadas para posteriores análises, com base no teor de matéria seca (MS), obtido em estufa à $105^{\circ} \mathrm{C}$ até o peso constante, de acordo com o método no 1.1 .02 da AOAC (1995). O percentual de proteína bruta (PB) foi determinado pelo teor de nitrogênio em aparelho de destilação a vapor micro-Kjeldahl adotando-se o fator de conversão de 6,25 conforme método no 31.1 .08 da AOAC (1995). Os percentuais de fibra em detergente neutro (FDN) e fibra em detergente ácido (FDA) corrigidos para cinzas, obtidos por meio de extração 
Tabela 1 - Análise bromatológica (\% de nutrientes na base da MS) das amostras coletadas por simulação de pastejo, disponibilidade de forragem $\left(\mathrm{kg} \mathrm{MS} \mathrm{ha}^{-1}\right)$ e percentual de folhas e colmos da pastagem de Brachiaria brizantha.

\begin{tabular}{|c|c|c|c|c|c|c|c|}
\hline & \multicolumn{6}{|c|}{ 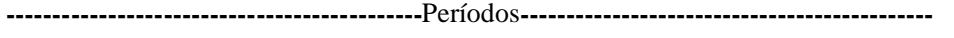 } & \multirow{2}{*}{ Eq. Regressão } \\
\hline & $23 / \mathrm{Fev}$ & 14/Mar & 05/Abr & 26/Abr & 17/Mai & 07/Jun & \\
\hline MS & 31,50 & 32,20 & 32,49 & 39,70 & 39,21 & 42,41 & $\mathrm{Y}=2,3654$ Per. $+27,97$ \\
\hline PB & 8,04 & 8,77 & 10,19 & 9,38 & 7,15 & 6,94 & $Y=-0,3191$ Per. $+9,52$ \\
\hline EE & 1,53 & 1,50 & 1,66 & 1,50 & 1,41 & 1,31 & $Y=-0,0437$ Per. $+1,63$ \\
\hline FDA & 36,87 & 37,08 & 37,99 & 39,84 & 40,69 & 42,23 & $\mathrm{Y}=1,1280$ Per. $+35,16$ \\
\hline FDN & 67,52 & 65,87 & 64,48 & 69,51 & 69,96 & 74,64 & $Y=1,5114$ Per. $+63,37$ \\
\hline MM & 7,13 & 6,93 & 6,31 & 6,23 & 6,14 & 5,63 & $Y=-0,2843$ Per. $+7,39$ \\
\hline $\mathrm{CNF}$ & 15,78 & 16,93 & 17,36 & 13,38 & 15,34 & 11,48 & $Y=0,8643$ Per. $+18,07$ \\
\hline DF & 1846,21 & 2573,68 & 3230,4 & 4478,11 & 5300,31 & 2710,31 & $\mathrm{Y}=392,8$ Per. $+1981,7$ \\
\hline$\%$ Folhas & 65,90 & 56,09 & 52,07 & 47,07 & 39,81 & 32,95 & $Y=-6,24$ Per. $+70,84$ \\
\hline$\%$ Colmos & 34,09 & 43,9 & 47,93 & 52,92 & 60,19 & 67,04 & $Y=6,24$ Per. $+29,15$ \\
\hline
\end{tabular}

Matéria seca (MS), Proteína bruta (PB), Extrato etéreo (EE), Fibra em detergente ácido (FDA), Fibra em detergente neutro (FDN), Matéria mineral (MM); Carboidratos não fibrosos (CNF); Disponibilidade de forragem (DF); Período experimental (Per.).

enzimática, foram determinados segundo metodologia descrita por VAN SOEST (1991). As análises dos teores de extrato etéreo (EE) e cinzas foram realizadas conforme metodologias no 31.4.02 e 31.1.04, respectivamente, da AOAC (1995).

A pesagem dos animais foi realizada, após jejum de sólidos de 12 horas, no início do experimento e, posteriormente, a cada 21 dias. Nas mesmas ocasiões, foram realizadas as mensurações corporais: altura da cernelha - correspondente à distância da cernelha até a superfície do solo; altura da garupa - correspondente à distância do osso sacro até a superfície do solo; perímetro torácico - perímetro caudal à escápula passando pelo esterno e pelos processos espinhais das vértebras torácicas; perímetro escrotal - obtido medindo-se a região escrotal de maior diâmetro; perímetro da canela - mensurado a partir do diâmetro na altura do osso metacarpiano no membro anterior direito e comprimento corporal - linha reta entre a articulação escápulo-umeral e a tuberosidade coxal do ílio, tomada lateralmente com fita métrica.

O ganho em peso médio diário (GMD) por período experimental foi obtido pela diferença entre os pesos final e inicial de cada período experimental (21 dias), dividido pelo número de dias do período. $\mathrm{O}$ ganho em peso médio diário total (GMDt) foi obtido pela diferença do peso final e o peso inicial dividido pelo tempo total do experimento (126 dias). A cada pesagem, os animais foram submetidos à avaliação subjetiva do escore de condição corporal (ECC), conforme RESTLE et al. (1977).

O GMD dos períodos experimentais foi analisado em delineamento experimental inteiramente casualizado, com arranjo fatorial 2x6 (dois níveis de suplementação e seis períodos experimentais) por meio da análise de medidas repetidas no tempo pelo procedimento MIXED do software estatístico SAS (2002), de acordo com o seguinte modelo matemático: $\mathrm{Y}_{\mathrm{ijk}}=\mu+\mathrm{a}_{\mathrm{i}(1 ; 2}+\mathrm{R}_{\mathrm{j}}\left(\mathrm{a}_{\mathrm{i}}\right)+\left(\mathrm{a}_{\mathrm{i}} \mathrm{b}_{\mathrm{j}}\right)+\mathrm{b}_{\mathrm{j}(1 ; 2 ; 3 ; 4 ; 5 ; 6)}+\mathrm{E}_{\mathrm{ijk}}$ Em que: $\mathrm{Y}_{\mathrm{ijk}}=$ observações da variável depèndente correspondente ao nível de suplementação i, período experimental $\mathrm{j}$, e repetição $\mathrm{k} ; \mu=$ média de todas as observações; $\mathrm{a}_{\mathrm{i}}=$ efeito do $\mathrm{i}$ - ésimo nível de suplementação, sendo 1 e $2=0,5$ e 1,0\% do PV, respectivamente; $\mathrm{R}_{\mathrm{j}}\left(\mathrm{a}_{\mathrm{i}}\right)$ = efeito aleatório baseado na repetição dentro dos tratamentos; $a_{i} b_{j}=$ efeito da interação entre o i-ésimo nível de suplementação e jésimo período experimental; $b_{j}=$ efeito do j-ésimo período experimental, sendo 1,2,3,4,5 e 6; $\mathrm{E}_{\mathrm{ijk}}=$ erro experimental referente à observação do i-ésimo nível de suplementação, j-ésimo período experimental e repetiçãok.

As demais variáveis relativas apenas ao efeito dos níveis de suplementação (tratamentos) sobre o ganho em peso total e desenvolvimento corporal foram analisadas em delineamento inteiramente casualizado segundo o modelo matemático: $Y_{\mathrm{ik}}=\mu+$ $a_{i(1 ; 2)}+E_{i k}$ Em que: $Y_{i k}=$ observações da variável dependente correspondente ao nível de suplementação $\mathrm{i}$ e repetição $\mathrm{k} ; \mu=$ média de todas as observações; $\mathrm{a}_{\mathrm{i}}=$ efeito do i-ésimo nível de suplementação, sendo 1 e 2 = 0,5 e $1,0 \%$ do PV, respectivamente; $E_{\mathrm{ik}}=$ erro experimental referente à observação do nível de suplementação i e repetição k.

Os dados foram previamente submetidos à análise de normalidade pelo teste Shapiro-Wilk e as 
diferenças entre médias detectadas pelo teste $t$ com $5 \%$ de nível de significância máximo das análises. Realizaram-se ainda análises de regressão linear.

\section{RESULTADOS E DISCUSSÃO}

Na tabela 1, constam os resultados da análise bromatológica das amostras da forragem aparentemente consumida. Constatou-se, por meio da análise regressão, comportamento quadrático do teor de PB da forragem com decorrer dos períodos de pastejo, sendo observado aumento linear até o terceiro e diminuição do quarto até o sexto período. Entretanto, pode-se inferir que não houve limitação de compostos nitrogenados para o desempenho dos animais, pois os teores de PB da pastagem obtidos durante o experimento se apresentaram acima do valor mínimo sugerido por VAN SOEST (1994), que é de 7\% de PB na matéria seca.

Constatou-se aumento linear do percentual de MS com o avanço dos períodos. A análise de regressão linear permitiu estimar incrementos de 2,36 pontos percentuais no teor de MS por período experimental. Essa constatação está de acordo com a afirmação de FRIZZO et al. (2003) de que há aumento do percentual de MS com o avanço no estádio de desenvolvimento de plantas forrageiras. O mesmo comportamento foi observado com relação aos teores de FDN e FDA que aumentaram linearmente. Os teores de EE e MM se mantiveram constantes. Com o decorrer dos períodos de pastejo, houve diminuição e aumento, respectivamente, de 65,90 e 34,09\% (primeiro período) para 32,95 e 67,04\% (sexto período), na participação dos componentes folhas e colmos (Tabela 1).
NEUMANN et al. (2005), avaliando o desempenho de bovinos jovens suplementados em pastagem também verificaram redução de folhas de $43,0 \%$ para $21,38 \%$ e de 33,27 para $20,61 \%$, respectivamente, com a evolução dos períodos experimentais.

Constatou-se interação significativa $(\mathrm{P}<0,05)$ entre os níveis de suplementação e os períodos experimentais sobre o ganho em peso médio diário (Figura 1). Na medida em que evoluíam os períodos, com a progressiva diminuição da temperatura e dos índices pluviométricos, a qualidade nutricional, a disponibilidade de forragem e o percentual de folhas verdes diminuíram, resultando em queda do desempenho dos animais em ambos os tratamentos. Entretanto, os animais suplementados com alto nível (NA) foram menos sensíveis as alterações quantitativas e qualitativas da forragem e mantiveram o GMD mais elevado $(\mathrm{P}<0,05)$ e mais constante, resultando em maior $(\mathrm{P}<0,05) \mathrm{GMD}$ no período experimental total $(0,88$ vs $\left.0,62 \mathrm{~kg} \mathrm{dia}{ }^{-1}\right)$, ganho em peso total $(111,68 \mathrm{vs} 79,17 \mathrm{~kg}) \mathrm{e}$ peso final $(231,26$ vs $197,55 \mathrm{~kg})$.

O melhor desempenho dos animais do maior nível de suplementação (NA) também poderia ser explicado, em parte, pela maior disponibilidade de forragem resultante de eventual efeito de substituição neste tratamento. Entretanto, constatou-se que a disponibilidade de forragem e do componente folhas foi o mesmo para ambos os tratamentos, reforçando a tese de que as diferenças no desempenho em favor dos animais do grupo NA foram resultantes dos efeitos do nível de suplementação e sua interação com a redução no aspecto qualitativo da forragem. $\mathrm{O}$ maior nível de suplemento energético $(1,0 \%)$ determinou o melhor desempenho dos animais do grupo NA (Figura

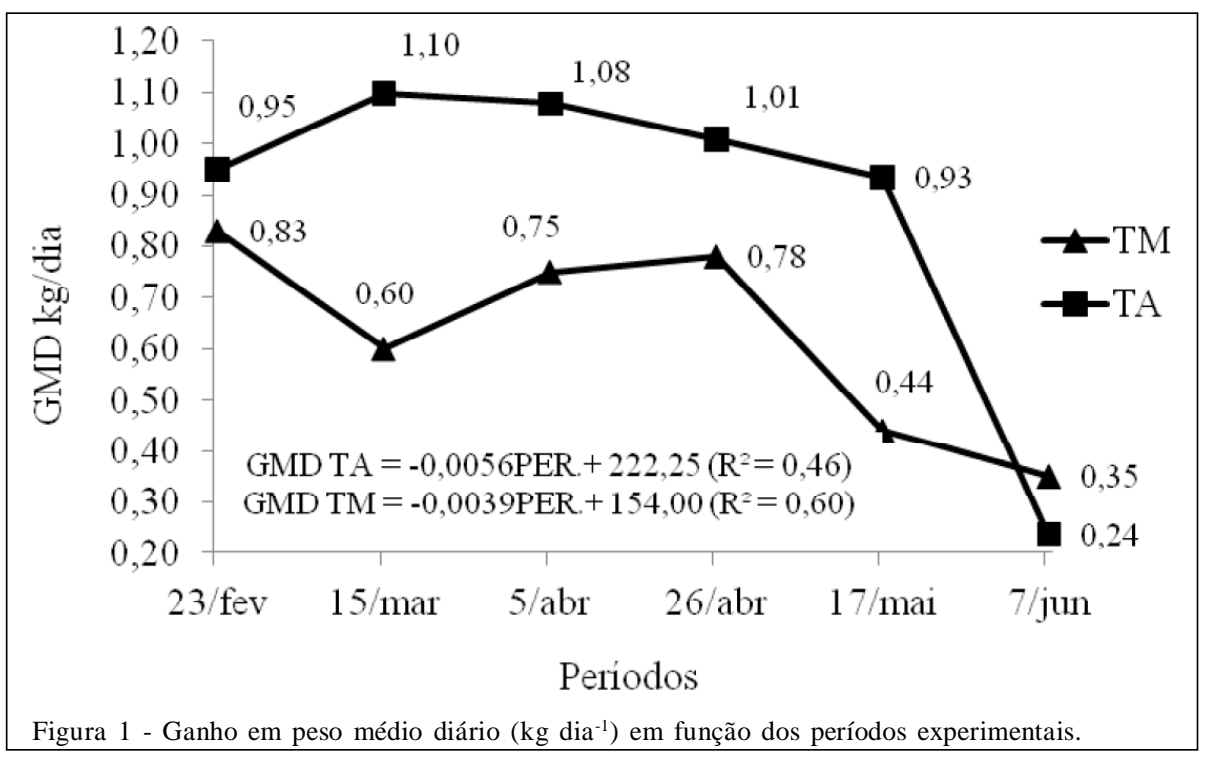

Ciência Rural, v.41, n.8, ago, 2011. 
1). Segundo NEUMANN et al. (2005), o desempenho dos animais em sistemas de suplementação em pastagem está relacionado à maior ingestão de MS e de nutrientes digestíveis totais contidos na fração concentrada ofertada aos animais.

Os animais que receberam alto nível de suplementação energética (NA) apresentaram maior $(\mathrm{P}<0,05)$ perímetro torácico (Tabela 2). Essa variável foi 39,69 e 6,56\% maior no ganho total (PTG) e na medida final (PTF), respectivamente, em favor do tratamento NA. O maior aporte energético resultante do maior nível de suplementação provavelmente permitiu maior disponibilidade de energia líquida para crescimento muscular dos animais deste tratamento.

Constatou-se diferença significativa $(\mathrm{P}<0,05)$ para as medidas finais de altura de cernelha (ACF) e garupa (AGF) em favor do grupo que recebeu alto nível de suplementação (NA), indicando que esses animais aumentaram o crescimento ósseo em função do maior aporte de nutrientes. Animais do tratamento NA foram mais altos $(\mathrm{P}<0,05)$ em 7,92 e 3,29cm nas medidas finais da garupa e cernelha, respectivamente.
Os animais do tratamento NA ganharam $2,22 \mathrm{~cm}$ a mais de perímetro escrotal que os animais do tratamento NM, no entanto, essa superioridade não foi suficiente para resultar em diferença significativa na medida final dessa variável (PEF) que apresentou valores de 22,77 e $24,67 \mathrm{~cm}$ para $\mathrm{NM}$ e NA, respectivamente. Segundo REZENDE et al. (2010), as medidas glandulares dos testículos de bovinos mestiços em crescimento variam de acordo com estádio de desenvolvimento sexual independente do nível alimentar.

As medidas de perímetro de canela não foram influenciadas $(\mathrm{P}>0,05)$ pelos níveis nutricionais, com valores médios de $16,26 \mathrm{~cm}$, evidenciando que essa medida não é precisa na quantificação do crescimento ósseo de bovinos mestiços suplementados em pastagem.

\section{CONCLUSÃO}

O fornecimento do suplemento em quantidade equivalente a $1,0 \%$ do PV mostrou-se

Tabela 2 - Médias e erros-padrão das medidas corporais $(\mathrm{cm})$ de mestiços de origem leiteira submetidos a níveis de suplementação energética em pastagem de Brachiaria brizantha.

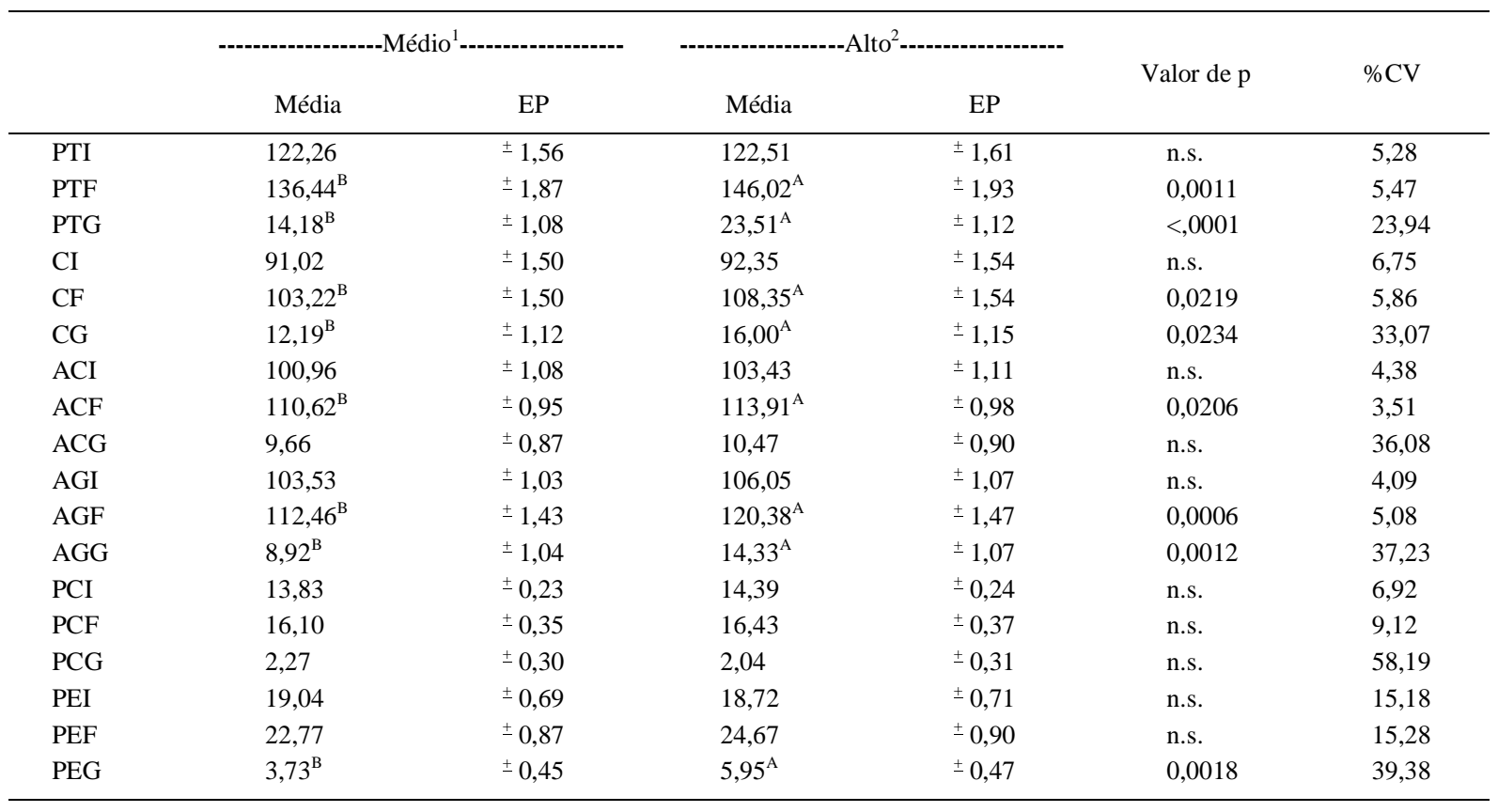

PTI - Perímetro torácico inicial; PTF - Perímetro torácico final; PTG - Ganho em perímetro torácico; CI - Comprimento inicial; CF Comprimento final; CG - Ganho em comprimento; ACI - Altura da cernelha inicial; ACF - altura da cernelha final; ACG - Ganho em altura da cernelha; AGI - Altura da garupa inicial; AGF - Altura da garupa final; AGG - Ganho em altura da garupa; PCI - Perímetro de canela inicial; PCF - Perímetro de canela final; PCG - Ganho em perímetro de canela; PEI - Perímetro escrotal inicial; PEF - Perímetro escrotal final; PEG - Ganho em perímetro escrotal; ${ }^{1} 0,5 \%$ do peso vivo em suplementação; ${ }^{2} 1,0 \%$ do peso vivo em suplementação; letras diferentes na linha indicam diferença estatística pelo teste $t(\mathrm{P}<0,05)$; EP - Erro padrão; CV - Coeficiente de variação; n.s. - Não significativo.

Ciência Rural, v.41, n.8, ago, 2011. 
tecnicamente mais atrativo por proporcionar aos mestiços menor oscilação de ganho em peso frente às alterações das características quantitativas e qualitativas da forragem com a evolução dos períodos e por favorecer o desenvolvimento corporal dos animais.

\section{REFERÊNCIAS}

ASSOCIATION OF OFFICIAL ANALYTICAL CHEMISTS AOAC. Official Methods of Analysis (red.). Washington DC, 1995, 1015p.

ELIZALDE, J.C., et al. Performance and digestion by steers grazing tall fescue and supplement with energy and protein. Journal of Animal Science, v.76, p.1691-1701, 1998. Disponível em: <http://jas.fass.org/cgi/reprint/76/6/1691>. Acesso em: 28 fev. 2009.

EUCLIDES, V.P.B. et al. Avaliação de diferentes métodos de amostragem para se estimar o valor nutritivo de forragens sob pastejo. Revista Brasileira de Zootecnia, v.21, n.4, p.691702, 1992. Disponível em: <http://www.revistasbz.org.br/scripts/ revista/sbz1/Resumo.asp?NumArtigo=724>. Acesso em: $28 \mathrm{fev}$. 2009.

EUCLIDES FILHO, K. et al., Desempenho de diferentes grupos genéticos de bovinos de corte em confinamento. Revista Brasileira de Zootecnia, v.32, n.5, p.1114-1122, 2003. Disponível em: <http://www.scielo.br/pdf/rbz/v32n5/ 17893.pdf>. Acesso em: 10 fev. 2009. doi: 10.1590/S151635982003000500011 .

FRIZZO, A. et al. Suplementação energética na recria de bezerras de corte mantidas em pastagem de inverno. Revista Brasileira de Zootecnia, v.32, n.3, p.643-652, 2003. Disponível em: $<$ http://www.scielo.br/scielo.php?script=sci_arttext\&pid=S1516$35982003000300016 \& \operatorname{lng}=e n \& n r m=i s o>$. Acesso em: $10 \mathrm{fev}$. 2009. doi: $10.1590 / \mathrm{S} 1516-35982003000300016$.

GIBB, M.J.; TREACHER, T.T. The effect of herbage allowance on herbage intake and performance of lambs grazing perennial ryegrass and red clover swards. Journal of Agricultural Science, v.86, p.355-365, 1976. Disponível em: <http:// jou rn a $1 \mathrm{~s}$. c a m b r i g e. or g/a c t i o n / displayAbstract? fromPage $=$ online $\&$ aid $=4790308>$. Acesso em: 10 fev. 2009. doi: 10.1017/S0021859600054824.

NEUMANN, M. et al. Desempenho de bezerros de corte em pastagem de capim elefante (Pennisetum purpureum Schum.) associado a diferentes níveis de suplementação. Ciência Rural, v.35, n.1, p.157-163, 2005. Disponível em: <http:// www.scielo.br/scielo.php? script $=$ sci_arttext\&pid $=$ S0 103 $84782005000100025 \& \operatorname{lng}=\mathrm{en} \& \mathrm{nrm}=\mathrm{iso}>$. Acesso em: $10 \mathrm{fev}$. 2009. doi: 10.1590/S0103-84782005000100025.

RESTLE, J. et al. Efeito do desmame precoce na carcaça de novilhos terminados em pastagem e abatidos aos 24 meses. Pesquisa Agropecuária Brasileira, v.34, n.11, p.2129-2136, 1999. Disponível em: <http://webnotes.sct.embrapa.br/pab/ pab.nsf/ecd4ca 3 ff 88 efcfa 032564 cd 004 ea $083 /$ ea 5 e 24 c 86 bbc $693483256856006590 \mathrm{cc} / \$ \mathrm{FILE/}$ pab98_029.pdf>. Acesso em: 10 fev. 2009. doi: 10.1590/ S0100-204X1999001100020.

REZENDE, P.L.P. et al. Morfometria testicular de bovinos mestiços jovens submetidos a diferentes estratégias de suplementação energética de pastagem de Brachiaria Brizantha. Ciência Animal Brasileira, v.11, n.04, p.817-824, 2010. Disponível em: <http://www.revistas.ufg.br/index.php/vet/ article/view/7642/8355>. Acesso em: 10 fev. 2009. doi: 10.5216/cab.v11i4.7642.

SAS INSTITUTE. SAS/STAT user's guide: statistics. 6.ed. Version 8. Cary, NC, 2002. V.2, 943p.

SILVA, D.J.; A.C. QUEIROZ. Análise de alimentos (métodos químicos e biológicos). 3.ed. Viçosa, MG: Universidade Federal de Viçosa, 2002. 235p.

VAN SOEST, P.J. Nutritional ecology of the ruminant. 2.ed. Ithaca: Cornell University, 1994. 476p.

VAN SOEST, P.J. et al. Methods for dietary fiber, neutral detergent fiber, and nonstarch polyssacarides in relation to animal nutrition. Journal of Animal Science, v.74, n.10, p.3583-3597, 1991. Disponível em: <http://www.scielo.br/ scieloOrg/ph p/reflinks.php?refpid=S 1516 $3598201000040001900014 \& \mathrm{pid}=\mathrm{S} 1516$ $35982010000400019 \& \operatorname{lng}=$ en $>$. Acesso em: 10 fev. 2009. 